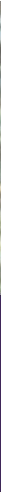

CIFOR infobrief provides concise, accurate, peer-reviewed information on current topics in forest research

\title{
Exploring the forest - poverty link
}

\section{Key points}

- In exploring the link from forests to poverty alleviation, two key questions arise: What role can forests and forestry play in the efforts to reduce poverty in developing countries? And to what extent do forests help prevent extreme hardship, even when they don't reduce poverty?

- A striking gap exists between, on the one hand, the neglect of forests in economic development and poverty reduction strategies and on the other, the high (and sometimes unrealistic) expectations regarding the role for forest products in parts of the forest literature.

- From a macro-level perspective, economic growth normally does trickle down to the poor, at least over time and at aggregate scales. The forest literature tends to ignore this effect, including the impact of forest rents flowing into other sectors.

- Non-timber forest products (NTFPs) serve subsistence needs, can have important 'gap filling' functions and sometimes provide regular cash income. However, there is a strong association between poverty and NTFP dependence. Paradoxically, the same characteristics that make NTFPs important and attractive to the poor, also limit their potential for increasing incomes.

- Timber has traditionally been the rich man's lot but the current trends of increased local control over natural forests, smallholder tree growing and small scale, wood-based enterprises may somewhat modify this picture.

- The realm of payments for ecological services is expanding rapidly and has a huge potential but the extent to which the poor will benefit remains uncertain.

- The choices relating to livelihood and poverty definitions, concepts and indicators clearly influence policy and project design, as well as research results and interpretations.

- Particularly promising topics for future study are identified within the fields of: assessing current forest-based benefits to the poor; exploring emerging market opportunities; and evaluating cross-cutting institutional and extra-sectoral issues.

\section{Forests and poverty - a controversial link}

On a global scale, among an increasing number of donors and national governments, reducing poverty has become the general focal point for development initiatives. In fact, Poverty Reduction Strategies (PRS) are providing the key framework for projects and interventions in many developing countries. Accordingly, significant shifts have occurred in the positions assumed by some of the major actors in the international forest development arena, reflected in documents such as the World Bank's new Forest Strategy and the Food and Agriculture Organization's policy brief on how forests can be made more pro-poor. But how much of this new paradigm is based on the real potentials of forests to benefit the poor and how much is simply an opportunistic shift in rhetoric? While forestry has taken a significant step to incorporate poverty reduction into its general discourse, the reverse cannot be said, in terms of the role forests can play in poverty alleviation being recognised in broader economic development and poverty reduction strategies.

\section{Poverty and economic growth}

Many micro-level forest practitioners observe that new income sources only benefit the few, so they remain skeptical about the role of economic growth in reducing poverty. However, our review of the macro-level literature shows that economic growth normally does trickle down to the poor, at least over time and at aggregate scales. In general, the poverty record of economic growth is thus better than its reputation. Poverty reduction without growth is conceivable but in practice, extremely difficult to achieve. The politicaleconomy obstacles to redistribution are much larger if one needs to take away a piece of a stagnant sized cake from the rich, rather than have them accept sharing whatever increment there is in the cake. 


\section{Poverty - definitions, concepts and indicators}

The choices regarding livelihood, poverty and forest concepts and indicators have important implications for any evaluation of the poverty alleviation potential of forests. The traditional definition of poverty was a materialistic one, focusing on a lack of income and material possessions. In recent decades, the concept has been extended to include other, nonmaterial aspects of human well-being, like health, education, nutrition and even security and empowerment. Compared to per capita income, these are valuable additional dimensions of human welfare but unfortunately they are less tangible, measurable and comparable. Hence, it can be useful to analyse or think about poverty causes in broader terms (for example, using the 'Sustainable Livelihoods Approach', looking at a number of the factors that matter for poor people and the means for achieving these things) but to measure poverty using indicators closer to the original meaning of the term.

Here, we use the term 'poverty reduction' to describe a situation where people become measurably better off over time, in absolute or relative terms - i.e. they are 'lifted out of poverty' when they climb above a pre-defined poverty line. In contrast, 'poverty prevention' refers to the role of forests in helping people to survive and maintain a minimum standard of living - i.e. referring to the insurance and gap filling functions of forests in cushioning poverty, without lifting people above the poverty line. 'Poverty alleviation' encompasses both terms. The definitions of 'forests' and 'forestry' also have important repercussions on the evaluation of how important tree-based systems are for poor people. 'For example, are 'trees on farms' included? And do valuation figures include the value added in downstream activities or are they just based on the value generated in and near the forest?"
Generally speaking, the most 'pro-poor' growth paths emphasise the following five factors:

- More and better education

- A rural development focus

- Labour-intensive products and technologies

- Reductions in the price of staple foods

- Good governance

\section{Using forests to cushion and reduce poverty}

Tens of millions of people depend on forests as a dominant source of subsistence and cash income, while hundreds of millions depend on forest products in some supplementary way. Our review of the actual and potential role of forests in poverty alleviation distinguishes three benefit categories:

- Non-timber forest products (NTFPs)

- Timber

- Ecological services

\section{Non-Timber Forest Products (NTFPs)}

Non-timber forest products cover a wide range of products with different characteristics. Some serve subsistence needs, others have important gap filling or safety net functions and a few provide regular, important cash income. Most NTFPs are labour intensive, require little capital and skills, are openly accessible for extraction and provide generally poor prospects for market and price growth. Unfortunately, this combination makes the majority of NTFPs economically inferior products, yielding low returns for those engaging in their production and trade. Paradoxically, the same characteristics that make them important and attractive to the poor (as an employment of last resort'), also limit the potential for increasing NTFP

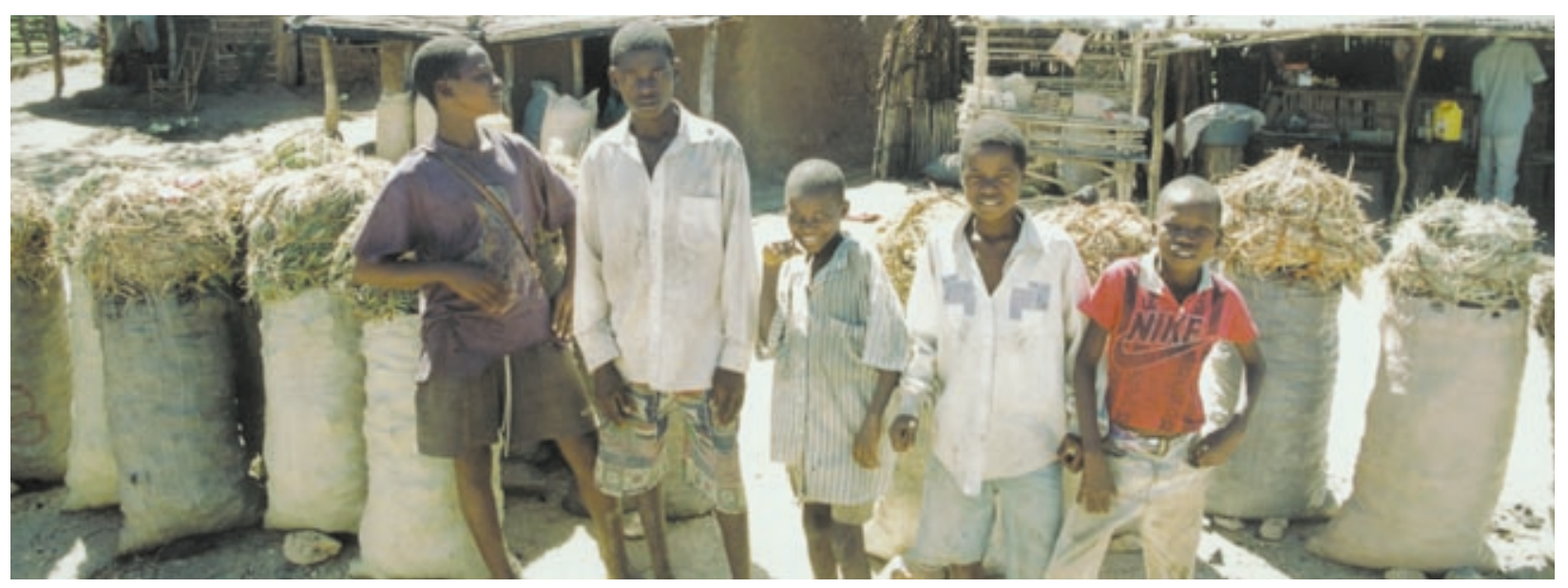

Roadside sellers of charcoal - produced from the dry forests and miombo woodlands of central Mozambique (Gorongosa, Sofala province). Charcoal is one of the main cash sources in this poor region but its production also contributes to forest degradation. (Photo by Sven Wunder) 


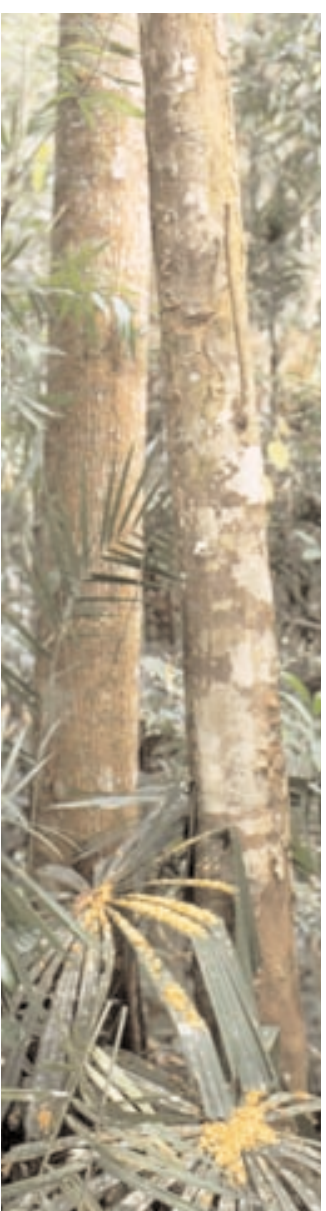

incomes. Yet, there are also some exceptions that fall outside this main pattern - products that are managed more intensively, have better market prospects and provide higher economic returns. However, research over the past ten years has shown that the great enthusiasm about NTFPs as general income generators was somewhat misplaced - they are not the 'silver bullet' that some had hoped for.

\section{Safety net or poverty trap?}

There is a strong correlation between dependence on non-timber forest products and rural poverty, although the causal relationship between the two is less clear. In some cases, NTFPs provide important livelihood contributions to people with limited or no alternatives. They can also play a role in poverty prevention and helping people survive - in which case they can hardly be called a 'poverty trap'. However, as they rarely provide the means of socioeconomic advancement, they are normally poor instruments for poverty reduction.

NTFPs and other extractive forest products are currently threatened, both from overexploitation and habitat destruction. In regions across the developing world with dismal prospects for national economic development, the main challenge may be to maintain the supply of NTFPs and their role as a safety net, particularly for the very poor - unless other activities and resources can take on that role. In some cases, the role of forests as key safety nets may only be transitory, as poor people diversify and build other assets to insure themselves against a variety of risks.

\section{Timber}

If NTFPs have normally been the poor person's lot, it is the rich who have mostly captured the benefits from precious tropical timbers, due to a number of production and market characteristics (high capital and skill intensity, land tenure requirements, technology, production systems, time horizons, more specialised markets, etc.). Still, this general anti-poor verdict overlooks the fact that, over time and space, some of these pro-rich rents normally do trickle down to the poor, through indirect channels (e.g. employment, profit reinvestment at the national level and multiplier effects) and through local development impacts (like road building). In terms of direct poverty reduction for local people, three timber-based pathways appear promising:

- Increased local control over natural forests

- Smallholder tree growing

- Small scale, wood-based enterprises

Increased local ownership of natural forests could make certain timber sub-sectors more pro-poor in the future, mainly by improving the negotiating position of local people for claiming their share of timber rents.
Increasing commercialisation of lower-value wood for fibre, pulp or construction timbers can also help the poor, for example, through the creation of outgrower schemes and contractual arrangements between companies and smallholders. Small scale wood processing is also providing significant and growing employment in many areas. A number of recent changes in technology, markets and institutional frameworks (including control over forestland) are favouring this trend. However, some of these pro-poor opportunities come at the cost of deforestation and forest degradation. Unfortunately, most of them also benefit the moderately poor, rather than the poorest of the poor.

\section{Ecological services}

Forests have always provided ecological services to the local people living in and around them. Recently, markets have also been developing where off-site 'buyers', sometimes far away from the forests, pay local people to preserve the flow of the ecological forest services they are interested in seeing maintained. The key areas include:

- Biodiversity

- Tourism

- Hydrological protection

- Carbon-sink functions

There is some ground for optimism that forestservice payments can help to reduce rural poverty, offering an additional source of income. Such payments tend to be more stable over time than the ones they are designed to substitute (e.g. the fluctuating prices of timber and cash crops). In addition, they can also induce a series of indirect benefits, follow up investments and external assistance (such as training and improvements in community organisation, local knowledge about forest management and environmental quality). However, there are uncertainties regarding how large and widespread such transfers will be - and to what degree poor people will be able to enter into these emerging markets. The poor are often disadvantaged by their insecure land tenure and the high transaction costs and risks that service buyers face in dealing with many smallholders or communities with internally divided interests.

Yet, in spite of these constraints, potential payments for forest based services all have a large global value and the increasing threats against them also enhance the users' willingness to pay to preserve them. Higher site-specificity and requirements for collective coordination across a larger area (e.g. to provide watershed protection or biodiversity corridors) can increase the ability of poor people to participate. The main challenge will be to design and experiment with institutional set-ups that include poor people as competitive suppliers of remunerated forest services. 


\section{Future research on poverty and forests}

Forests certainly have a role to play in poverty alleviation, although in most cases this is more likely to relate to prevention rather than reduction. However, both deserve to be the subject of further research in exploring the full potential of forests (i.e. focusing on both the poverty prevention/safety net functions of forests and on their potential for monetary income generation and poverty reduction). The resulting findings will help guide decisions to safeguard and increase the benefits poor people receive from forests. Research has already yielded key insights in some areas, for example, highlighting major obstacles that are preventing forests from playing a bigger role in poverty reduction. However, a large number of questions remain unanswered. Studies on how to measure and increase timber benefits to the poor remain scarce and research on ecological service payments has only recently started to build up, as markets for these services gradually develop.

As a result of this review, we have selected what we believe to be the ten most promising areas for future research, under three over-arching umbrellas: assessing current forest-based benefits for the poor; exploring emerging market opportunities; and evaluating crosscutting institutional and extra-sectoral issues.

The highest priority themes within these areas are:

1. Natural forest products in household livelihoods (focusing on both safety nets and increased welfare)

2. Small scale wood-based processing enterprises

3. Globalisation, trade liberalisation and forest-product markets

4. Smallholder tree planting and private sector partnerships
5. Payments for forest environmental services

The second highest priority we assign to the following topics:

6. Economy wide benefits from forest-based rents

7. On-site ecological forest services

8. Local resource control and land tenure

9. Decentralisation, governance and forest-market deregulation

10. Integrating forests into macroeconomic strategies

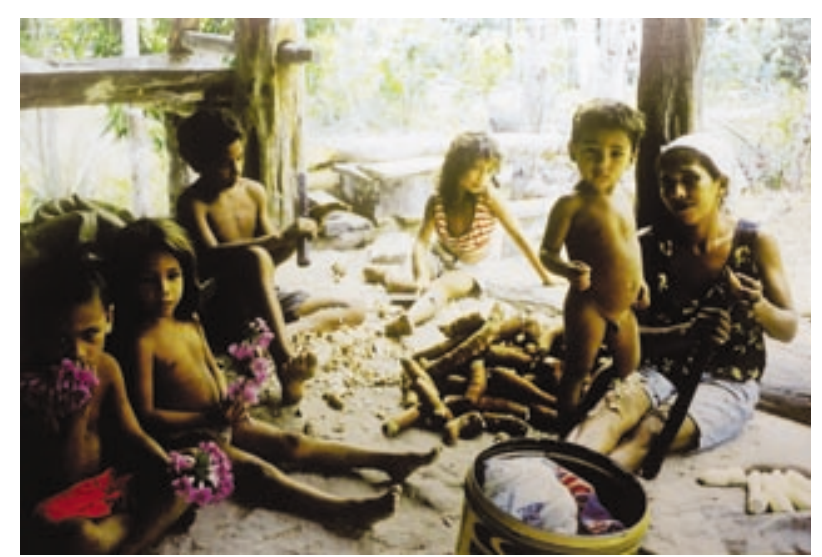

Forests have both potentials and limitations in regard to poverty alleviation, with possible roles as safety nets, poverty traps and pathways out of poverty. Poor people living in and near forests (like this family in the Rio Capim area, Pará State, Brazil) are the ones who are most dependent upon forests for their livelihoods. (Photo by Sven Wunder)

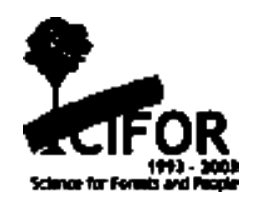

This infobrief is based on text from Angelsen, A. and Wunder, S. 2003 Exploring the forest - poverty link: Key concepts, issues and research implications. CIFOR Occasional Paper No. 40. Center for International Forestry Research, Bogor, Indonesia. Project funding and support was received from CIFOR and the UK Department for International Development (DFID).

\section{Department for} Development

Center for International Forestry Research

office: Jalan CIFOR, Situ Gede, Sindang Barang, Bogor Barat 16680, Indonesia. mailing: P.O. Box. 6596 JKPWB, Jakarta 10065, Indonesia Tel: +62(251) 622622 Fax: +62(251) 622100

E-mail: cifor@cgiar.org Website: www.cifor.cgiar.org

Cover photos: Carol J.P. colfer, Michael Hailu, Sven Wunder and Alain Compost

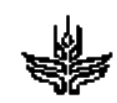

